\title{
Publicaciones Recibidas
}

\section{ARGENTINA}

De la Academia Argentina de Letras: Boletin: Tomo I (1933), $\mathrm{N}^{\circ} 4$ (2 $2^{\text {ed.; }}$ 1946); tomo II (1934), Nos. 5 y 6; 7 y 8 ( $2^{\text {a }}$ ed., 1943); tomo III (1935), Nos. 9 y 10 ( $2^{\mathrm{a}}$ ed., 1946), y completos los tomos desde el 41 al 78 (1943-1951).

Discursos académicos (4 tomos): Acuerdos acerca del idioma (2 tomos). además:

Andrade, Olegario Víctor, Obras poéticas, Estudio. Texto de Eleuterio F. Toscornia. Díaz, Leopoldo, Antología. Prólogo de A. Navarro.

Groussac, Paul, Mendoza y Garay (2 tomos). Prólogo de Carlos Ibarguren.

Gutiérrez, Juan María, Los poetas de la Revolución.

Lugones, Leopoldo, Diccionario etimológico del castellano usual.

Mármol, José, Poesías completas (2 tomos). Textos y prólogo de R. A. Arrieta. Mitre, Bartolomé, Defensa de la poesía. Estudio preliminar y notas de Matiano de Vedia y Mitre.

Oyuela, Calixto, Textos bispanoamericanos (2 tomos).

- Estudios literarios (2 tomos). Prólogo de Alvaro Melián Lafinur.

Vélez Sarsfield, Dalmacio, La Eneida (libros I a VII). Trad. de. Prólogo de Juan Alvarez.

Zaldumbide, Gonzalo, Cuatro grandes sláricos americanos.

Editorial Castelv|, San Martín 2355. Santa Fe.

Ambrosetti, Juan B., Supersticiones y leyendas (1953);

Ascasubi, Hilario, Poesias para el pronunciamiento de Urquizo (1956);

Buonocore, Domingo, El mundo de los libros (1955); Vocabulario bibliográfico (1952);

Cambaceres, Eugenio, Obras completas (1956);

D'Aló, Oreste A., Algunos bombres; algunas ideas (1955);

Danero, E. M. S., Antología gaucba (1956);

Finó, J. Frederic y Hourcade, Luis A., Tratado de Bibliologia (1954);

Gionello, Leopoldo, José de San Martín (1956);

Gollán, Josué (h.), La alquimia (1956);

Hume, Rolando, El legado del montonero escocés (novela, 1956); Nuevo enfoque agrario (1956); El hombre como medida de la economia (1955); 
Editorial Claridad, San José 1621. Buenos Aires.

Ravines Eudocio, América Latina. Un continente en erupción (1956).

Colegio Libre de Estudios Superiores. Talleres Continental. Lavalle 1671, Buenos Aires.

Germani, Gino, Integración politica de las masas y el totalitarismo (1956).

La Editorial Columba de Buenos Aires [domicilio: Sarmiento $1889,5^{\circ}$ piso, Buenos Aires] nos ha enviado los siguientes libros de su ya prestigiosa Colección Esquemas:

1. Francisco Romero, Qué es la filosofía (1953);

2. Jorge Luis Borges, El "Martin Fierro" (1953);

3. Julio E. Payró, El Impresionismo en la pintura (1953);

4. Vicente Fatone, Introducción al existencialismo (1953);

5. Marcos Victoria, Qué es el psicounálisis (1953);

6. Carmelo M. Bonet, Escuelas literarias (1953);

7. Jorge Romero Brest, Qué es el arte abstracto (1953);

8. José Luis Romero, La Cultura occidental (1953);

9. Julián Marias, Idea de la metafisica (1954);

10. Alfredo L. Palacios, Masas y élites en Iberoamérica (1956);

11. Ismael Quiles, S. J., Qué es el Catolicismo (1954);

12. Luis Juan Guerrero, Qué es la belleza (1954);

13. B. Foster Stockwell, Qué es el Protestantismo (1954);

14. Alvaro Melián Lafinur, El Romanticismo literario (1954);

15. Francisco Romero, Ubicatión del bombre (1954);

16. José María Monner Sans, Introducción al teatro del siglo XX (1954);

17. Vicente Fatone, El Hombre y Dios (1955);

18. Guillermo de Torre, Qué es el superrealismo (1955);

19. José Babini, Qué es la ciencia (1955);

20. Marcos Victoria, Introducción a la psicologia (1955);

21. Julio E. Payró, Que es el "Fauvismo" (1955);

22. Bernardo A. Houssay, La investigación cientifica (1955);

23. Osvaldo Loudet, Qué es la locura (1955);

24. Rafael Alberto Arrieta, Introducción al modernismo literario (1956);

25. Rodolfo Mondolfo, El Genio belénico (1956);

26. Desiderio Papp, Qué es el átomo (1956).

Como puede comprobarse por los nombres de los autores que firman los trabajos y la variedad de los temas tratados, la Colección Esquemas tiene un interés de primer orden en la difusión y mantenimiento de las más diversas exigencias de la cultura en esta parte del mundo hispánico. La mayoría de esos autores son argentinos, o bien hombres de reconocido prestigio mundial incorporados a la vida argentina, en donde desarrollan su labor en la cátedra, las casas editoras, las revistas, los diarios, etc. Los investigadores científicos y literatos argentinos con cuyos nombres se garantiza la seriedad de esta colección, son también personas que constituyen hoy el núcleo ejemplar de la vida moral e intelectual de la culta república del Plata. Los "esquemas" que se ofrecen, de alrededor de unas setenta 
páginas cada uno, son en todo momento la exposición sintética, abarcadora en sus esencias o constantes de grandes momentos de la cultura o de aspectos específicos de sus diversas manifestaciones. La Colección, que tiene apenas tres años de vida, se encuentra en pleno desarrollo. Por su calidad y utilidad estos "esquemas" están destinados a convertirse en los compañeros imprescindibles de estudiantes, profesores y toda otra persona que se interese por la historia de la cultura, su actualización y su sentido dinámico y formativo. Cada uno de nuestros lectores escogerá el título a que lo lleven sus preferencias. El filósofo hallará en Francisco Romero, Rodolfo Mondolfo, Julián Marías o Vicente Fatone la madurez y el ajuste de quienes viven la dignidad de la disciplina que cultivan; Bernardo Houssay, premio Nóbel de la ciencia en la Argentina, José Babini, Desiderio Papp, Marcos Victoria y Osvaldo Loudet se concretan a aspectos de la investigación científica más especializados; la estética y la literatura tiene síntesis magistrales en los títulos que firman Guerrero, Arrieta, Guillermo de Torre, Romero Brest, Borges y Moner Sans; la religión ofrece los panoramas de los dos sectores más universales del cristianismo: el católico, a cargo del P. Quiles, y el protestante, confiado a Stockwell. Por último, los contrastes entre culturas como la europea y la de América Latina se exponen en dos libros admirables por su claridad y rigor, el de José Luis Romero sobre La Cultura Occidental y el de Alfredo L. Palacios sobre Masas y élites en Iberoamérica. (A. A. R.).

Instituto Amigos del Libro Argentino. Beauchef 287. Buenos Aires. Boletin, número 14; Bibliograma, número 15.

Editorial Lautaro, José E. Uriburu 1225. Buenos Aires.

Martínez Estrada, Ezequiel, ¿Qué es esto? (1956);

Rodríguez, Alberto (h.), Matar la tierra (1955);

Editorial Posesión, Perú 973. Buenos Aires.

Loprete, Carlos Alberto, La literatura modernista en la Argentina (1955).

Editorial RaIgal, Sarmiento 730. Buenos Aires.

Girri, Alberto y Viola Soto, Carlos, Poesia italiana contemporanea (1956);

Lima, Jorge de, Poemas (1956);

Mastronardi, Carlos, Conocimiento de la noche (1956);

Navarro, Raúl, Poesia moderna del Brasil (1956);

Rodríguez Araya, Agustín, Nuevas bases (1956);

Ruiz, Luis Alberto, Diccionario de la literatura universal (1955; tres vols.);

Romero, José Luis, Argentina: imágenes y perspectivas (1956);

Shand, William y Girri, Alberto, Poesia norteamericana contemporánea (1955);

Villafañe, Javier, De puerta en puerta (1956);

Wilcock, Juan Rodolfo, Cuartetos de T. E. Eliot; traducción de (1955); 
Editorial Sur, San Martín 689, Buenos Aires.

Borges, Jorge Luis, Otras inquisiciones (1952);

Girri, Alberto, Linea de la vida (1955); Examen de nuestra causa (1956);

Murena, H. A., El pecado original de América (1954); La fatalidad de los cuetpos (1955); El centro del infierno (1956);

Ocampo, Victoria, Virginia Woolf en su diario (1954);

Onetti, Juan Carlos, Los adioses (1954);

Salas, Alberto, Relacion parcial de Buenos Aires (1955);

Editorial Troquel, Vidt 2826, Buenos Aires.

Borges, Jorge Luis, Leopoldo Lugones (1955);

Du Bos, Charles, ¿Qué es la literatura? (traducción de Ernesto F. Babino (1955).

Editorial ReConstruir. Director: L. Danussi. Casilla de Correo 320, Buenos Aires.

Universidad Nacional del Litoral.

Universidad. Revista oficial de la U. N. del L. Bulevar Pellegrini 2750, Santa

Fe. Números 30, 31 y 32. Años 1955 y 1956.

Buonocore, Domingo, Bibliografia literaria $y$ otros temas sobre el editor $y$ el libro (1956);

Lasso de la Vega, Javier, La selección de libros (1956);

Boletin Informativo, Año I, números 1 y 2 [mimeografiado].

Reconstruir. Periódico semestral "por el socialismo y la libertad", Año X, números 61-74 (menos el 68);

A. Camus, Ni víctimas ni veráugos;

G. Enestau, Reivindicación de la libertad;

L. Franco, Anates y después de Caseros;

H. Read, Arte, poesia, anarquismo;

R. Rocker, La voluntad de poder como poder bistórico;

F. Romero, Alejandro Korn como la libertad;

H. E. Roqué, Origen del socialismo moderno;

A. Souchy, Capitalismo, democracia y socialismo libertario.

J. P. Warbasse, El cooperativismo puede evitar la guerra.

\section{BRASIL}

La LivRaria Jose Olimpin Editôra nos ha enviado:

Ivone Azevedo, A. face mutàvel; María Eugênia Celso, Poesias completas y Osman

Lins, $O$ visitante.

Sabemos que esta casa editora tiene en circulación otros títulos, que esperamos para prestarles la debida atención en nuestras páginas. 


\section{COLOMBIA}

Hemos recibido Espiral, revista de artes y letras de Bogotá, Vol. VII, númeto 62, correspondiente a junio de 1956. Contiene: "Sor Francisca Josefa de la Concepción", por Darío Achury Valenzuela; "El concepto de la novela en Ortega y James", por Nilita Vientós Gastón; "Cuatro sonetos y una canción" por Dora Castellanos; "El hombre en la plástica americana", por Jacinto Hernández; "El horizonte está en frente", por Raúl González de Cascorro, y "La muerte sonreida" (teatro), por Joaquín Piñeros Corpas. Además: Notas, Reseñas y Noticias de actualidad.

Espiral. Revista Mensual de Artes y Letras. Bogotá, noviembre de 1956. Contiene: Clementé Airó, "Ocio y creación"; Waldo Ross, "Hombre y tiempo de las dos Américas"; Andrés Holguín, "tierra humana (poema); Antonio Aparicio, "Cuando la luz asomaba"; "Mosaicos y esculturas en la Universidad de Caracas"; Tulio M. Cestero, "Sangre solar"; Reyes Carbonel, "Guerra civil" (poema). Además, una interesante sección de Notas.

4. CUBA.

Instituto Nacional de Cultura. Ministerio de Educación. Palacio de Bellas Artes. Nímero extraordinario del Boletin Informativo, correspondiente a julio de 1956 y cuya dirección estuvo a cargo de la doctora Marlyn Ichazo. Trae interesante material ilustrativo e informativo.

Comisión Nacional Cubana de la UNESCO. Su Boletin correspondiente al Año V, número 6, junio, 1956, contiene: "Berta Arocena, una precursora", por Francisco Ichazo; "Homenaje a Ortega y Gasset", por Humberto Piñera Llera; "Educación de la comunidad en México", por Rafaela Chacón Nardi; "Hasta aquí otra vez", por Salvador Bueno; "Exposiciones", por Ramón Loy; "Musicales", por Odilio Urfe, y un "Calendario", de conferencias, conciertos, exposiciones y funciones teatrales, que registra la actividad cultural de Cuba durante el mes de mayo de 1956.

Ciclón. Revista Literaria. Vol. 2, Núm. 5. Septiembre de 1956. Director: José Rodríguez Feo. Contiene: Julio Rodríguez Luis, "Recuerdo de Mariano Brull"; Adolfo Bioy Casares, "De cada lado"; Humberto Rodríguez Tomeau, "La aventura"; Antón Arrufat, "Admisión"; Luis Marré, "Folia"; Luis Suardiaz, "Las voces"; Lionel Trilling, "Arte y neurosis"; Carlos E. Sánchez, "Gettatore"; Rubén Vela, "La bestia del cielo". Y una sección de reseñas titulada "Barómetro".

\section{EL SALVADOR.}

El Ministerio de Cultura. Departamento Editorial, El Salvador, C. A., ha encomendado al prestigiado hombre de letras Trigueros de León la publicación de una "Biblioteca Popular", que integran autores nacionales, y de la que hemos recibido ya una docena de títulos, a saber: 
Vol. 1. Alfredo Espino, Jícaras tristes (1955);

Vol. 2. Francisco Miranda Ruano, Las voces del terruño (1955);

Vol. 3. Salarrue, El Cristo negro (1955);

Vol. 4. Miguel Ângel Espino, Mitología de Cuscatlán (1955);

Vol. 5. Alberto Rivas Bonilla, Andanzas y malandanzas (1955);

Vol. 6. Alberto Masferrer, Una vida en el cine (1955);

Vol. 7. Emilio Campos, Normas supremas (1955);

Vol. 8. Arturo Ambrogi, Muestrario (1955);

Vol. 9. Salvador Calderón Ramírez, Aquino, Morgan y Paterson (1955);

Vol. 10. León Sigüenza, Fábulas (1955).

Vol. 11. Napoleón Velazco, Cisneros, El Pintor (1955);

Vol. 12. Rafael Heliodoro Valle, Flor de Mesoamérica (1955).

Como se ve, en un año de labor el señor Trigueros de León ha cumplido, con extraordinaria y hasta increible eficacia en medios tan exiguos, con la misión que se le ha encargado. El mismo, escritor limpio y crítico penetrante, es un ejemplo de gusto y sobriedad. Por eso, la selección de esta "Biblioteca Popular", hecha con esmeto y rigor de valores, es una muestra de cómo, al decir de Taine, el arte es a la vez aristocrático y popular, ya que dice las más altas cosas para una mayoria. "Biblioteca Popular" del Ministerio de Cultura de El Salvador cumple con nobleza y sentido común.

El mismo Departamento Editorial publica también la "Colección contemporáneos", cuyos títulos aparecidos hasta la fecha son:

1. Manuel Andino, Vocación de marino (1955);

2. Hugo Lindo, Guaro y champaña (1955;

3. Juan Antonio Ayala, Cifra de bumanidad (1955);

4. Francisco Herrera Velado, Agua de coco (1955);

5. Trigueros de León, Perfil en el aire (1955).

Esta colección, dirigida también por Trigueros de León, posee calidad semejante a la anterior.

El mismo Departamento Editorial nos ha enviado, además, las siguientes publicaciones:

Arturo Ambrogi, El libro del trópico (1955);

Walter Béneke, El paraiso de los imprudentes (1956);

Julio Fausto Fernández, El libre albedrio (1956);

Claudia Lars, Escuela de pájaros (1955);

T. P. Mechin, Burla burlando (1955).

El Ministerio de Cultura ha iniciado, además, tres colecciones: 1) De poesia, que lleva publicados dos volúmenes: Juan Cotto, Cantos de la tierra prometida (1955) y Margarita Paz Paredes, Presagio en el viento (1955); 2) De historia, cuyo volumen 1 es: Jorge Larde y Larín, José Simeón Cañas (1956); y 3) Biblioteca minima, que se inicia con Manuel Ángel Espino, La vida de José Simeón Cañas (1955). 
EL SALVADOR (Ministerio de Cultura).

Cultura. Revista del Ministerio de Cultura, número 7. Enero-Febrero 1956. Director: Manuel Andino; Secretario de Redacción: Juan Antonio Ayala. Contiene: Lujio Icaza Tejerino, "La muerte en la poesía de Rubén Dario"; Luis Rosales, "La Adolescencia de Don Quijote"; Alberto Quinteros (h.), "En el centenario del nacimiento de G. B. Shaw"; Enrique Labrador Ruiz, "Me llamo barro aunque miguel me llame"; Salvador Cañas, "Un nuevo libro de Trigueros de León"; Augusto Monterroso, "Jorge Luis Borges"; Juan A. Ayala, "Algo más sobre los géneros literarios"; Alfredo Betancourt, "Esquema práctico de la función instructiva"; "Gustavo Pineda, "Breve historia de César"; Trigueros de León, "Nuestros poetas y la historia literaria"; "Pintores salvadoreños"; Jorge Carrera Andrade, "Ignacio Flores el primer escritor satírico americano"; Miriam Tal, "Tendencias en escultura"; José Bruin, "Elogio del piropo"; José María Méndez, "Disparatario"; Sebastián Vega (h.), "Chontales"; y otras colaboraciones y noticias.

Guión literario. Publicación del Departamento Editorial del Ministerio de Cultura. San Salvador. Números 5, 6, 7, 8; mayo, junio, julio, agosto de 1956;

Ayala, Juan Antonio, Lydia Nogales. Un suceso en la historia literaria de El Salvador (1956);

Fernández, Julio Fausto, Patria y jwentud en el mundo de boy (1956);

Masferrer, Alberto, Estudios y figuraciones sobre la vida de Jesús (1956);

Rubio, Victor Daniel, Orden y libertad en la educación y otros ensayos (1956);

Sáenz, Vicente, Morelos y Bolivar (1956);

Valdés, José, Poesiat pura (1956).

\section{ESPAÑA.}

La Casa Americana de Madrid nos ha enviado dos números (1 y 2) de Atlántico, Revista de Cultura Contemporánea (junio, 1956); el número 2 contiene un valioso material de ensayos y notas críticas que firman Manuel García Blanco, José A. Balseiro, John Englekirk, George Hamilton, George R. Harrison, José Luis Cano, Bernardo Villarrazo, John E. Keller y John T. Reid. Es una publicación de la Embajada Norteamericana en España.

La Casa Americana, de la Embajada de los E. U. en España, publica también una serie de cuadernillos de difusión popular que titula Noticias de actualidad. Son publicaciones semanales. El último número que hemos recibido cortesponde al 2 de julio de 1956.

Insula. Publicación de la Librería de Ciencias y Letras (Carmen 9, Madrid), de Luis Canito. Hemos recibido el número 123. Tanto los artículos y reseñas como la bibliografía que trae son de suma utilidad para conocer la actividad çultural españolạ de hoy. 


\section{ESTADOS UNIDOS DE NORTEAMERICA.}

Pan American Union, Washington 6, D. C.

Hemos recibido: Revista Interamericana de Bibliografia, Vol. VI, Núm. 1, eneromarzo, 1956. De gran valor bibliográfico. Imprescindible para conocer el movimiento cultural de Iberoamérica. Américas, Vol. 8, Núm. 7, julio de 1956. Número especial en conmemoración del Congreso de Panamá de 1826. Contiene: Andrés Iduarte, "Bolivar y la independencia americana"; Antonio Carrillo Flores, "México en marcha"; Georges D. Landau, "Moderno Instituto de aeronáutica del Brasil"; Ricardo J. Bermúdez, "Vieja y nueva Panamán", y notas de Gil Blas Tejeira, Carlos Spinedi y Ch. G. T.

\section{MEXICO.}

La Libreria Studium (Apartado 20979, Adm. 32) nos ha enviado la serie completa de la "Colección Studium" y de los "Manuales Studium", que dirige el profesor Frank de Andrea. [Véase aviso en este número].

Estos manuales, cuyo plan abarca las literaturas de todos los países de América latina, son de suma utilidad. Confiado cada uno a especialistas de reconocido prestigio en el mundo hispánico (Arturo Torres Rioseco, Luis Leal, F. Dauster, Zum Felde, Anderson Imbert, Mead, Fernando Alegría, etc.), enfocan y exponen, en forma sintética y necesaria, aspectos generales y sobresalientes de la producción literaria hispanoamericana, como el ensayo, la novela, el modernismo, la poesía, o bien nos dan panoramas de las literaturas de cada país. En este último sentido, consideramos un modelo en su género la Breve bistoria de la literatura chilena, que corresponde al manual número 1, de Arturo Torres Rioseco, recientemente dado a la circulación. (A. A. R.).

Abside. Revista de cultura mejicana. XX-3. Julio-septiembre de 1956. Contiene colaboraciones de Joaquín Antonio Peñalosa, Luis Medina Ascensio, S. J., J. M. González de Mendoza, Gregorio Marañón, Alfonso Junco, José María Pemán, Oscar Méndez Cervantes y se reproducen traducciones de Manuel José Othón y Ambrosio Ramírez. Se prosigue la publicación de la corres. pondencia entre R. Foulché-Delbosc y Alfonso Reyes y se inserta una carta sobre Nervo de Juan Zorrilla de San Martín; Idem, XX-4, octubre-diciembre, 1956. Director Alfonso Junco. Contiene: "Ábside cumbre veinte años" (La Dirección); Octaviano Valdés, "El barroco, espíritu y forma del arte de México"; Antonio Gómez Robledo, "Octaviano Valdés en la Academia"; Francisco Alday, "Amor del nuevo cántico"; José María Pemán, "El tiburón"; Eduardo Carranza, "Menéndez Pelayo y nosotros"; Fray José Alvarez, "Duarte y Virgilio" (Carta al Director de Abside); Esther M. Allison, "Profunda España"; Silvino Robles Gutiértez, "Miguel Bernal Jiménez. La última charla del maestro".

Estaciones. Revista literatia de México. Año 1, Núm. 1, Primavera, 1956. Editores: Elías Nandino y Alfredo Hurtado. Dirección: Ali Chumacero, Alfredo 
Hurtado, José Luis Martínez, Elias Nandino, Carlos Pellicer. Distribuidor: Obregón, S. A., Av. Juárez 30, México, D. F.

Esta revista que "aparecerá cson el ritmo de las estaciones del año", se abre con "La 'Obra soñada' de Mallarmé,", por Alfonso Reyes y se completa con un excelente material de poesías, prosa imaginativa, crítica literaria, notas, noticias y un "Suplemento en homenaje a la memoria del poeta y pintor peruano César Moro. Idem, Año I, Núm. 3, Otoño de 1955. Editores: Elías Nandino y Alfredo Hurtado. Contiene: Alfonso Reyes, "La reacción contra Goethe"; Miguel Guardia, "Elegía"; José Luis González, "La despedida de Laura"; Salvador Reyes Nevares, "Notas sobre el surrealismo"; Mario Puga, "Antonio Machado: el hombre y la política"; Fernando Sánchez Mayáns, "Poema a un artista difunto"; Salvador Echevatria, "Surrealismo y babelis. mo"; María Luisa Hidalgo, "Epica del gusano"; Enriqueta Ochoa, "La sequía"; St. John Perse, "Nieves" (Traducción de J. Moreno de Tagle); Ermilo Abreu Gómez, "Notas sobre poesía americana"; María Amparo Dávila, "Gar" den Party del olvido"; Elías Nandino, "Después del surrealismo... ¿qué?"; Rubén Salazar Mallén, "Diagnóstico de una traición". Notas de Alfredo Hurtado Hernández y Arturo Rivas Sáinz. Suplemento con estudio y antología del surrealismo.

\section{Fondo de Cultura Económica.}

La Gaceta. Año III, Nú, 25. Dedicado al Congreso por la Libertad de la Cultura. Año III, Núm. 26. Homenaje a Alejandro Korn (Evocación de R. Lida).

Celestino Gorostiza, Teatro Mexicano del Siglo XX, Vol. III;

Fernando Benítez, La ruta de Hernán Cortés (2da. edición);

José Luis Romero, Las ideas politicas en Argentina (2da. edición).

Revista Mexicana de Literatura, Núm. 5. Mayo-junio de 1956. Responsables: Carlos Fuentes y Emmanuel Carballo. Contiene: Jorge Lezama Lima, "Fiestas oscilantes"; Eduardo Anguita, "La visita"; Braulio Arenas, "Poesía"; José Vázquez Amaral, "La poesía norteamericana contemporánea" [Estudio y traducción por]; Ricardo Garibay, "Alemán tomando cerveza"; Saki, "Laura"; Daniel Cosío Villegas, "Rabasa entre dos constituciones"; Kostas Papaionannou, "La teoría de la ideología"; Octavio Paz, "La poesía de Carlos Pellicer"; J. M. Cohen, "Marvell y el barroco español"; Laurette Séjourné, "El mito náhuatl de la resurrección". Textos de Jaime Torres Bodet y Jaime García Terrés sobre "La responsabilidad del escritor"; Cheng Ch'u-Hui, "Los caballos bailarines" y una sección crítica denominada "Talón de Aquiles".

Porria Hnos. y Cia.

Boletin Bibliográfico Mexicano. Noviembre-diciembre de 1956. Trae una breve selección de Prosa y Verso de Juan Ramón Jiménez.

Studium. Gacetilla Bibliográfica Cultural de la Librería "Studium", Núm. 49, 15 de octubre de 1956. 


\section{NICARAGUA.}

La Universidad Nacional de Nicaragua, León, Nicaragua, nos ha enviado los cinco números de los Cuadernos Universitarios que lleva publicados hasta eneromarzo de 1956. Dirige Dr. Roberto Arana Navas. Alternan en sus páginas trabajos originales y reproducciones. El material es variado y de muy diversa calidad.

\section{URUGUAY.}

Cuademos Herrera y Reissig. Ediciones.

Di Gíorgio Medicis, Marosa y Varela, Luis Alberto, Dos poetas [selección de ambos poetas]. Núm. 45, Montevideo;

González Garcés, Miguel, Diez poetas gallegos. Núm. 43, 1956;

Roggiano, Alfredo y Palley, Julián, Elegías y otros poemas (1956);

Moratorio, Arsinoe, La última garza (1956);

Mural de poesias. Director: Luis Alberto Varela. Entregas de 1954 y 1955.

\section{VENEZUELA.}

Ministerio de Educación. Dirección de Cultura y Bellas Artes. Hemos recibido: Revista Nacional de Cultura, Núm. 115, marzo-abril de 1956. Director: Manuel F. Rugeles.

En sus dieciocho años de vida, esta revista ha mantenido su alta calidad,y es hoy una de las mejores consideradas de la América hispánica. El número 115 se prestigia con las firmas de Mariano Picón-Salas, Guillermo de Torre, Luis Alberto Sánchez, Fernando Díez de Medina, entre las prosas de ensayos, y con los de Manuel F. Rugeles y Carlos Bousoño entre los poetas. Tiene una abundante y valiosa sección de reseñas y otra dedicada al "Panorama de las ideas", que esta vez está a cargo de Juan David García Bacca, Jorge Campos, Héctor García Chuecos, R. Di Prisco y C. Montiel Molero. (A. A. R.).

El No. 117-118 de la misma Revista, correspondiente a julio-octubre de 1956, Contiene: Centenario de Menéndez y Pelayo, "Valores Hispánicos: Retrato de Don Marcelino Menéndez y Pelayo"; Mariano Picón-Salas, "Menéndez y Pelayo leído otra vez"; Pedro Pablo Barnola, "Menéndez y Pelayo ante la obra de Bello"; Pedro Grases, "El juicio de Menéndez Pelayo sobre Rafael María Baralt".

Letras: Edoardo Crema, "Arte, mistagogía y mitos"; Guillermo Meneses, "Venezuela"; Hugo Emilio Pedemonte, "Panorama de la actual literatura uruguaya; Vitelio Reyes, "Sesquicentenario de la Bandera Nacional"; Simón Romero Lozano, "Guillermo Morón: el pensador y el escritor"; Israel Peña, "A un siglo de su sombra"; Guillermo Morón, "Historia de una posibilidad"; Federica de Riteter, "El soneto. Su forma e historia'; obra de Walter Mönch"; 
Jacobo Bentata, "Poesía árabe"; Wesley G. Woods, "La poesía inglesa del siglo xx"; Jean Aristeguieta, "Asís es piedra de leyenda viva".

Poesía: Octavio Paz, "¿No hay salida?"; Miguel Otero Silva, "Elegía coral a Andrés Eloy Blanco"; Oscar Rojas Jiménez, "Muerte de un labrador"; Rafael Āngel Insausti, "Soledad"; José Ramón Medina, "En el límite". Panorama de las ideas: Francisco Romero, "Alejandro Korn, filósofo de la libertad"; Juan D. García Bacca, "Comentarios a la 'esencia de la poesía' de Heidegger"; Victoriano Tejera, "La filosofía y el arte poético"; "Estampas de Venezuela; Emilio Boggio, "Un maestro del impresionismo". Trae, además, una importante sección de reseñas denominada "Libros" y otra de "Noticias" y "Actualidades".

La misma Dirección de Cultura y Bellas Artes nos envía los cuadernos de poesías números 16, 17 y 18, en lujosas ediciones, que pertenecen a Carlos Gottberg, Estrictamente bumano (16); Pedro Rafael Gilly, Ventanal sonoro (17), y Rafael Pineda, La caza del unicornio (18).

Asociación de Escritores Venezolanos. Recibimos el cuaderno literario número 90, que corresponde a los cuentos Las bormigas viajan de noche, de Antonio Márquez Salas.

Colección Letras Venezolanas. Recibimos los números 3 y 4 de esta valiosa colección. Son dos volúmenes de crítica historiográfica, el número 3, Evolución de la bistoriografía en Venezuela, de Ramón Díaz Sánchez, y el número 4, Examen de la poesía venezolana contemporánea, de José Ramón Medina. El primero abarca, en prieta síntesis, los momentos básicos del movimiento historiográfico en Venezuela. El autor, Ramón Díaz Sánchez, hombre de acción e investigador, cuentista, novelista y miembro de las academias venezolanas de la Lengua y de la Historia, muestra en este cuaderno de diecinueve páginas su competencia erudita y su personal interpretación del tema que trata. Por su parte, José Ramón Medina, en su Examen de la poesía venezolana contemporánea, nos ofrece un útil panorama crítico desde la generación del año 18 hasta nuestros dias. El cuaderno se terminó de imprimir en Caracas, en junio de 1956. De modo que es de la mayor actualidad. El autor, poeta laureado con el premio "Boscán" en Barcelona y con el "Municipal" en Caracas, director de la revista literaria Shell, universitario y viajero por Europa, revela una alta sensibilidad de poeta, a la cual sujeta su crítica, siempre personal, como ocurre con todos los poetas. En estos casos interesa menos la subjetividad de los juicios que el rico conjunto de sugerencias que de ellos se desprende. El "Examen" cumple acabadamente con su fin. Si de todos los países de la América hispánica tuviéramos panoramas semejantes a éste, estaríamos mejor enterados de la poesía del continente, a veces tan ignorada inclusive en los mejores tratados de literatura hispanoamericana. (A. A. R.). 
